\title{
USING THE FORCE OF REPRESENTATION
}

\section{The New Hope Against the Rise of White Nationalism}

\section{Casey Walker}

\section{Abstract:}

Christine Cornea's article "From Isolationism to Globalism: An Overview of Politics and Ethics in the Hollywood Science Fiction Film" discusses the discourse on nationalism, isolationism, and the fear of globalization in Hollywood's science fiction films beginning in the 1930s. Cornea concludes these films have an "overwhelming concern with the defence [sic] of the nation throughout this period" and notes "the frequent narrative emphasis on confrontation (whether competitive, threatening, or violent) across circumscribed borderlines." These filmic manifestations of normative anxiety concerning migration and the immigrant "Other" create a space in which nativism and annihilation of immigrants are celebrated. However, in the most recent installments of the Star Wars franchise, Episodes VII \& VIII, the films advocate a more global, borderless society where humans and aliens coexist in a united front of resistance against the Empire. The racial diversity of the human characters further accentuates this conscious effort on the part of the studio and filmmakers to make inclusion and diversity the heart of the resistance against an Empire, which itself is emblematic of the mostly white, mostly male hierarchy of nativism and exclusion. This paper will use previous literature (such as the article mentioned above) to launch a discussion of the ways in which the latest installments in the Star Wars canon subvert the tradition of nationalist and nativist tendencies in science fiction films, creating a diverse resistance, while also serving as fertile ground for a response to the rise of nationalism (specifically white nationalism) in our nation today.

Keywords:

Star Wars, White Nationalism, Diversity

When The Walt Disney Company acquired Lucasfilm toward the end of 2012, with the promise of new films and media outside of the control of the franchise's creator George Lucas, fans and media critics alike were eager to see the direction the studio would take the Star Wars universe. 
The franchise's reputation was seen as somewhat diminished after the three financially successful prequel films didn't meet a commensurate critical success with many fans and critics. At the same time as this major acquisition for Disney, the white nationalism and alt-right movements, two groups that at least partially overlapped, were on the rise in the US, due in part to the nationalist rhetoric growing out of public figures such as then businessman Donald Trump and the websites Breitbart and InfoWars. Decades of media studies literature shows that science fiction films have always functioned as an outlet for growing geopolitical anxieties (Susan Sontag, 1965; Mick Broderick, 1993; Christine Cornea, 2017), but these films often reinforced a nationalist ideology that distanced Aliens as harmful 'Others' bent on challenging the dominance of a mostly male, mostly white power structure and always resulting in the 'Other's' defeat or assimilation (Charles Ramírez Berg, 1989). These Aliens served as imagery for racialized 'Others,' gendered 'Others,' immigrant 'Others,' queer 'Others,' and many more. But as the 2010's brought us the emergence of the white nationalist movement, they also brought us a growing cinematic response to that movement with films such as Monsters (2010) and Arrival (2016). This paper will argue that the most recent Star Wars films released after Disney's acquisition of Lucasfilm, Episode VII: The Force Awakens and Episode VIII: The Last Jedi, serve as a fertile discursive space for the growing anxieties over the rise of the white nationalist movement in the United States over the last decade. Unlike previous Star Wars trilogies, Episodes VII and VIII foreground the 'Other' in juxtaposition to the whiteness that the Empire and First Order represent both figuratively and literally. By incorporating a more diverse array of characters, such as people of color, women, and immigrants, the Resistance is juxtaposed against the mostly white, mostly male First Order in these films. This has led to the First Order being read by many as an obvious symbol of the white nationalism movement, as it strives to maintain its own perceived superiority over the resistance of 'Others.' Nicholas G. Evans of The Boston Globe commented on the obviousness of this reading, stating, "the alt-right must be the only people in the galaxy shocked at the parallels." In addition to the deepening diversity of the Resistance, the messaging of the new trilogy (specifically Episode $X I I I)$ deconstructs the inherent exceptionalism that played such a major part in the earlier trilogies' mythos, where greatness results from lineage and tradition over everything else. Members of the white nationalist and alt-right movements were not oblivious to both this messaging and the increase in diversity and thus vehemently and bitterly attacked the franchise and many of its stars on social media and digital platforms, while also attempting to co-opt Imperial and First Order imagery into the branding of their movement to distinguish themselves as the resistance to the Resistance. By exploring these recent films as case studies, and looking at the white nationalist response, this article will show how science fiction films can become cinematic responses that step from the edge and enter the center of discourse on the struggle against the current nationalist political movement.

Science fiction films have always served as productive ground for discourse regarding international social and political concerns. Looking at science fiction movies from 1950-1965 in her article "The Imagination of Disaster," Susan Sontag refers to this as a reflection of "worldwide anxieties" about identity and individual psyche, but argues the purpose of these films was to diminish these anxieties, not to serve as a form of social criticism. ${ }^{2}$ But it's Christine Cornea's article "From Isolationism to Globalism: An Overview of Politics and Ethics in the Hollywood Science Fiction Film" that focuses the discussion of these "world-wide anxieties" around the issues of nationalism, isolationism, and the fear of globalization. Following the evolution of Hollywood's science fiction films from the 1930 s through the 1960s, Cornea argues we see a resistance or 
hesitancy to fully oppose nationalism in these films. The article concludes with the open-ended question of how future science fiction films will document growing anxieties over current international events and specifically mentions (now President) Donald Trump, and his "highly isolationist stance on foreign policy" as a possible impetus to these fears. 3

This "highly isolationist stance" is a direct product of what is referred to as 'Neo-nationalism', an international movement that emerged in the early 2010s, defined as an amalgamate of civic nationalism, ethnic nationalism, and populism. President Donald Trump is seen as one of its biggest proponents and disseminators. Using the 'Other' as a scapegoat, Trump called for a wall protecting our border with Mexico, promised increased immigration enforcement, and declared he would institute a travel ban targeting visitors from Middle Eastern nations. 'Alt-right' websites such as Breitbart and Infowars, the latter led by internet and radio personality Alex Jones, joined forces with Trump during the campaign, helping spread his message and giving him a platform through which to build his base of supporters. A significant portion of these supporters of the altright movement subscribe to what is commonly being referred to now as 'white nationalism', defined by Eric Kaufman (2016) as "the belief that national identity should be built around white ethnicity, and that white people should therefore maintain both a demographic majority and dominance of the nation's culture and public life." 4 It is this movement of nativism and its support of Trump that has steadily increased international anxieties and tensions, the spark of which could ignite a world-wide powder keg at any moment. It is also worth noting that this movement does not just represent white nationalism, but specifically white male nationalism, with respect to both the movement's tenets and its agenda of maintaining the white male power structure. The movement's apparent absence of female leadership or even abundant representation further enforces the notion that white nationalists are not only interested in maintaining their perceived racial dominance, but their perceived sexual dominance as well, as men such as Patrick Casey, Richard Spencer, Gavin McInnes, Alex Jones, and groups such as The Proud Boys make up the public face of white nationalism. However, there are women involved in the ranks of both the alt-right and white nationalist movements, and as much as their involvement in these movements may be marginalized by the leadership, their involvement in spreading the rhetoric of white male nationalism and expanding its membership base should not be discounted either. USA Today and other publications have published stories about the difficulty these movements have in expanding this female membership, though, noting, "how the leadership of far-right groups has portrayed women in the media and [created] a culture of excluding women from certain groups and in certain instances advocating for violence against women." 5 Thus, given these movements' treatment of women, both inside and outside of the organization, it's important that when we think of the concept of the 'Other', that we understand with respect to the white nationalist movement the term not only applies to non-whites and non-Americans, but in most cases non-males.

It is in the midst of these growing global tensions over the rise of neo-nationalism, and its white male nationalist component, that Director JJ Abrams, who was hired to direct the first of the new Disney Star Wars films, Episode VII: The Force Awakens, and Producer Kathleen Kennedy aimed to fix the dearth of race and gender diversity in the original Star Wars films, and thus serve as a potential reaction to the white male nationalist movement. The two filmmakers, with assistance from initial screenwriter Michael Arndt and later Lawrence Kasdan, crafted the concept of the film and were thus responsible for the approach to making the new Star Wars films more diverse than those under Lucas. This approach included diversifying both the representation 
of the humans and the Aliens of the film, giving both more space on the screen and more agency in the story. Kennedy was also adamant that a female character would be "extremely significant" to the plots of the upcoming films, a term she used in an interview where she revealed the majority of her development and executive teams were women, many of them women of color. "Having a balance of men and women in the room changes the story," she said. ${ }^{6}$ Kennedy, with the aid of Abrams and the screenwriters, managed to create a wonderful female protagonist in Rey (Daisy Ridley), in addition to other female characters such as now General Leia, Maz Kanata, Captain Phasma, and others. By adopting a female protagonist, the filmmakers assisted the franchise in abandoning its long-standing tradition of depicting what Thomas Schatz calls the "age-old male initiation rite" as the "spine of the film," and instead focusing on the desperately underrepresented female initiation rite. 7 Kathleen Kennedy also saw to ensuring an "extremely significant" female protagonist in the franchise's first "stand-alone" film, Rogue One: A Star Wars Story (2016) in Jyn Erso. Valerie Frankel calls both Rey and Jyn "a new kind of heroine" that are "respected fighters, equal partners with the men, who are never sexualized or stripped" and "both defeat the male villains and save the day, emphasizing their competence." 8 The character of Rey (and later Jyn) helped Kennedy and Abrams create the balance they sought with respect to female voices in the story.

Kennedy and Abrams also hoped to create a racial balance in the film, bringing characters of color to the forefront, such as Finn (John Boyega) and Poe (Oscar Isaac) to complete a triumvirate of diverse primary characters with the addition of Rey. Through both casting and visual representation in the finished film, Kennedy and Abrams were helping the Star Wars franchise to shed the whiteness and maleness of its previous films, while also using the literal whiteness of the stormtroopers uniform to symbolically position the First Order as a symbol of the white male power structure opposing the Resistance. At one point, early in Episode VII: The Force Awakens, Finn sheds the stormtrooper helmet he is wearing in protest to the violent atrocities just committed by his fellow soldiers on innocent civilians. This is the moment where Finn discovers he can no longer be a part of the First Order and by shedding his helmet and later his uniform, he sheds not only the whiteness that the stormtrooper uniform represents, but also sheds the burden of its implied racism, sexism, and colonialism. The similarities between the representation of these uniforms and that of the white sheet and hood wore by the Knights of the Ku Klux Klan are telling, especially in group settings, which almost resemble a hybrid between Klan and Nazi rallies. Kylo Ren even refers to the warriors he leads as the Knights of Ren. Similarities also exist between certain renderings of the symbol for the KKK and the symbol for the First Order, both circular with a symmetrical intersection of lines within it. 

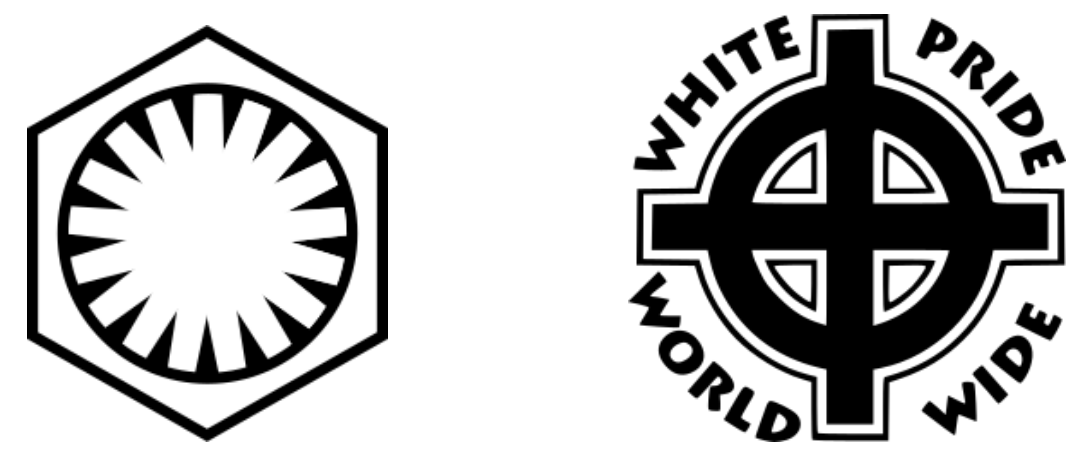

Figure 1 \& 2: The Symbol of the First Order (left) and the symbol for the KKK (right). First order image licensed under the Creative Commons Attribution-Share Alike 4.0 International license.

The character of Finn doesn't just shed the symbolic whiteness of the uniform, but also the name the First Order gave him: FN-2187. The assigned name sounds more like a serial number of something you own, which harkens back to the dark history of slavery. Just as slaves were given new names upon becoming property of slave-owners, so is Finn given the name of FN-2187. "It's the only name they ever gave me," he tells Poe shortly after meeting him. Poe suggests the name of Finn and the slave name of FN-2187 is abandoned. This abandonment of one's slave name became popular in the 1960's and 1970's with the rise of the Black Power movement, and was most famously undertaken by Muhammad Ali when he publicly denounced and cast aside the name he was given at birth, Cassius Clay.

Rey also wears a helmet when she is first shown on screen, hiding her identity from the viewer. We see her scavenge knowledgably and resourcefully amidst the abandoned wreckage of Imperial ships. When she finally removes her mask, her identity subverts our expectations, as previous Star Wars films would rarely give this valuable screen time solely to a female character. In fact, she also consistently surprises the other characters in the film. When she handles attackers in the Jakku marketplace, Finn stops dead in his tracks as he watches her dispatch the assailants with ease. Later, Han Solo is not only surprised by her knowledge of spaceship technology, but also her skills as a pilot. "The girl knows her stuff," Han admits.

But Rey doesn't know everything, and her search for knowledge about her past and her place in the universe provides the narrative spine of her female initiation rite. This quest for understanding her identity weighs heavily on Rey in Episodes VII and VII, something Maz Kanata notices upon meeting her. "The belonging you seek is not behind you, it is ahead," Maz tells her. In other words, don't look back for meaning, look forward. This places Rey in direct contradiction to Kylo Ren and the First Order, which pride themselves on the past, in much the same way as the white nationalist movement does. Kylo Ren keeps the helmet of his grandfather, Darth Vader, as a token of the past that he honors. He speaks reverently of Vader and hopes to maintain his ideals, while snuffing out the Resistance, the biggest threat to those ideals. His reverence for the past is symbolically depicted in a room in which Kylo communicates with Supreme Leader Snoke. A holographic image of the old, white Snoke wearing regal robes towers over Kylo as the latter bows obediently to his master. Whereas Rey is encouraged to look forward to the future, Kylo is always looking back to the ways of the past. 
Kylo Ren represents white nationalism, but also specifically white male nationalism, as he serves as a psychological example of toxic masculinity, which researchers usually define as disorder that can include suppressing emotions, maintaining an appearance of toughness, and using violence as an indicator of power. ${ }^{9}$ Amidst his temper tantrums of rage and anger at feeling pain, he is confounded by his inability to master Rey, both mentally and later physically. "You know I can take whatever I want," he tells Rey, when she is his prisoner. But he can't and that proves to be a major impetus to his rage. When she largely defeats him in combat before the collapsing terrain separates them, Kylo Ren is called back to Supreme Leader Snoke where he must complete his training. The Supreme Leader believes that Ren's defeat has more to do with his lack of training than it does with Rey's own abilities, another example of the dismissive, misogynistic tendencies of the white male nationalism of the First Order. This reading of Ren, Snoke, and the First Order as symbols of white male nationalism had some unanticipated consequences, according to John Marcotte, founder of Heroic Girls, a group that promotes strong female role models:

"I've spoken with Disney people, and they were completely blindsided by the reaction to the new Star Wars characters. They put a huge investment into marketing and merchandising the Kylo Ren character. They presumed he would be the big breakout role from the film. They were completely surprised when it was Rey everyone identified with and wanted more of."10

These reactions to white male nationalism that manifest themselves in Episode VII: The Force Awakens would become an even larger part of the film's sequel, Episode VIII: The Last Jedi. Replacing J.J. Abrams, director Rian Johnson and Kathleen Kennedy took the central message of the first film and ran with it, emphasizing the dichotomy between the past and the future. As Rey continues her quest to discover her lineage, she is reminded not to look back. Luke tells her it's time for the Jedi to end and refuses to swoop in and become the hero of the Resistance, which would overshadow Rey's importance to the story. Despite Kylo Ren's protestations that Rey is "not a part of this story," the viewer is constantly reminded otherwise, as her story drives the narrative of the film even if her lineage is shown (at least in this film) to be immaterial to the story. Kylo Ren tells her that her parents were nothing but junk merchants that abandoned her and that she comes from nothing. Frankel notes this development marks "an end to the chosen one story (which privileged a single hero, most often white, young, and male) and emphasized that a galaxy of the underprivileged were now welcome to join the Resistance."11

This chosen one storyline that Frankel makes note of is common in the Hollywood male initiation rite in films like The Matrix and the Harry Potter films, and is something I refer to as 'inherent exceptionalism'. I define inherent exceptionalism as the belief that an individual or group is born extraordinary as a result of either their lineage or their status as a 'chosen one' character. Inherent exceptionalism is pervasive in the Star Wars franchise, as the Force is generally passed down through families, and it's also a prominent narrative component in the blitz of superhero films that began in the early 2000's with the $X$-Men and Spiderman franchises. Jason Dittmer argues that in the wake of $9 / 11$, the superheroes in these films "articulate a particularly American geopolitical vision and sense of self, which is often shorthanded as American exceptionalism." 12 But, as these inherently exceptional superheroes or chosen ones are consistently white males, this representation reinforces the erroneous conclusion drawn by white 
nationalists that somehow being a white male and being exceptional go hand in hand. Thus, by subverting the inherent exceptionalism so omnipresent in the Star Wars franchise, The Last Jedi enforces that anyone can be exceptional, including women, immigrants, and people of color. And they are exceptional because of their abilities, knowledge, and character, not because of their lineage.

Abandoning inherent exceptionalism helps reinforce the films central message of letting go of the past, something the First Order is unable to do. Yoda (or at least his spirit) helps Luke understand this lesson in The Last Jedi when visiting Luke on the planet Ahch-To. Believing it is time for the Jedi Order to end, Luke rushes to the planet's Jedi temple containing the sacred texts to burn it down, but can't go through with the act. Instead, Yoda summons a lightning storm that strikes the temple, setting it on fire. Luke believes this is Yoda's way of confirming it is indeed time for the Jedi Order to end, but Yoda explains the true message of destroying something sacred, telling Luke that "it is time for (him) to look past a pile of old books." Yoda continues, "Wisdom they held, but that library contained nothing that the girl Rey does not already possess." His final words to Luke nail the point home: "We are what they grow beyond. That is the true burden of all masters." To become the next generation of masters, we must learn from previous generations' mistakes, not revere and repeat them. Whereas the First Order, and the white male nationalism movement they represent, believe in preserving their heritage and the white, male power structure, the Resistance and the Jedi Order (or what's left of it) believe in burning it to the ground and letting a new generation learn from its mistakes.

The Last Jedi also increased the diverse on-screen representation of both women and people of color that started with The Force Awakens. New characters such as Admiral Holdo (Laura Dern) and Rose and Paige Tico (Kelly Marie Tran and Ngo Thanh Van) displayed unprecedented agency within the narrative, which Frankel notes marked "a new era" which "insisted on respect for women with its new competent professionals leading the charge." ${ }^{13}$ Members of the First Order also embodied representation of women and people of color within the ranks, but it's worth noting that essentially all of the high level officers of the First Order are white males, and Captain Phasma, the one prominent woman of the First Order is encased in a chrome uniform. Elizabeth Grosz argues, "Women have been objectified and alienated as social subjects partly through the denigration and containment of the female body." By containing the specificity of Phasma's body within the chrome uniform, the First Order is also containing her subjectivity. ${ }^{14}$ This mirrors the same containment of women in the white nationalist movement mentioned earlier in this article, as the patriarchal power structure largely marginalizes them. However, the women of the Resistance are featured prominently in leadership positions, in some cases outnumbering the number of men in the focus of the frame as much as 4-1. Also, women speak some of the most important and meaningful lines from the film. Toward the end of the film, Rose explains the fundamental difference between the First Order and the Resistance. "That's how we're going to win," she says. "Not fighting what we hate, saving what we love." 


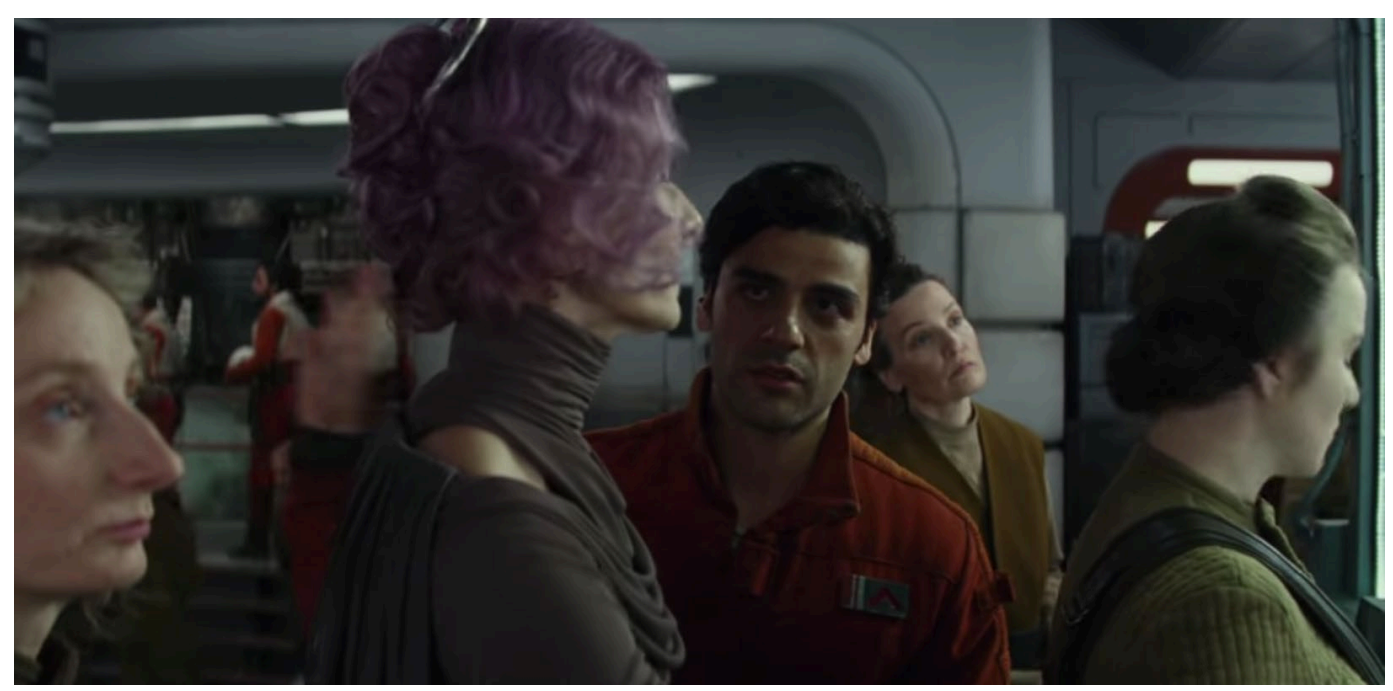

Figure 3. Screenshot from The Last Jedi with abundant female representation

This message against hate, in addition to the diverse representation and statements against inherent exceptionalism, was one of many perceived slights felt by the members of the actual white male nationalism movement that saw the film. The reaction was fierce from these groups and was instituted across multiple digital and social media fronts. The reaction became so bitter and intense, Kelly Marie Tran, who played Rose, abandoned usage of her social media platforms, as she became a target for online bullying and harassment. One group taking credit for its share of the backlash against the diversity and messaging of the franchise claimed it was doing so because of "more female characters [in] the franchise's universe" and wanted to see men "reinstated as rulers of society." 15 Others took exception to the increased racial diversity of the leads in the film, specifically John Boyaga and Tran. Members of these groups taking part in this campaign against the franchise expressed reverence for the original Lucas trilogy and hoped to see the franchise return to its perceived past greatness, echoing the First Order's great respect for the past. Even Mark Hamill, who played Luke Skywalker and fought against the online bullying of his co-stars, couldn't help himself and routinely criticized what he called "missed opportunities" for the new Star Wars films to honor the old characters and stories. Hamill's remarks only served to embolden some critics of the films' new directions and undermine the positive reception of their messaging of diversity and abandonment of inherent exceptionalism. Of those members of the white male nationalist movement seeing the representation of diversity and resistance in these films as a blow to their own messaging, some would incorporate Imperial and First Order imagery into their branding of their respective movements. Numerous alt-right and white nationalist groups deliberated online about utilizing figures such as Darth Vader, Emperor Palpatine, and others as symbols of their movement, leading one commenter to proclaim, "If Disney is going to directly push a connection between white supremacy and the Empire (they are), I say we use that to our advantage." 16 Other groups have used promotional enrollment paraphernalia with Imperial or First Order characters or imagery on them, encouraging people to "enlist" into the movement. Charlie Kirk's Turning Point USA conservative group recently posted a picture on Twitter of a man in a storm trooper costume protesting socialism on a college campus. ${ }^{17}$ Members of these white nationalist and alt-right groups are willing to co-opt this imagery of the films' antagonists simply to show their opposition to the ideals that the Resistance represents. 
The divisiveness employed by both the alt-right and white nationalist movements is all the more reason that the messaging of these films is so important. The increased diversity, messages against hate, and the abandonment of inherent exceptionalism in these new Star Wars films are not likely to convince the white male nationalist movement that their plight is hateful and destructive. But it is likely to inspire and hopefully convince the younger generation of moviegoers that the white male nationalist movement is indeed something that needs to be resisted. At the end of The Last Jedi, when the vastly depleted Resistance manages to escape the First Order, Rey asks General Leia, "How do we build a rebellion from this?" Leia pats Rey's hand and replies, "We have everything we need." In a way, Leia is speaking about Rey, but she is also speaking about the future of the Star Wars franchise. The last scene of the film shows young children telling each other the tales of the Resistance fighting the First Order, excited by the promise of a better future. The last shot of the film shows a young boy, inspired by the stories, looking up at the stars and hoping one day to join the Resistance. These are the minds that the films hope to change. Not the minds clinging to the traditions of the past, but those eagerly looking for the hope of a brighter future.

In the months after both the release of the films and the election of Donald Trump as President, real-life global events show us the dangers of white male nationalism. With a travel ban affecting Muslim countries, white nationalist rallies in cities like Charlottesville that turned deadly, tariffs against allied nations, and families seeking refuge at the border having their children separated from them and placed in cages, the world has now seen how the white nationalism movement treats the 'Other' and it's not kind. As the white nationalist movement displays cruelty toward immigrants and people of color, they have been equally cruel to the female 'Other,' as the confirmation of Supreme Court Justice Brett Kavanaugh and the events leading up to it have proven. As multiple accusers came forward alleging sexual misconduct by Kavanaugh, these women were harassed and bullied at the hands of the alt-right and white nationalist supporters. The \#MeToo movement, which has given hope to many women who have suffered abuse, harassment, and underemployment from men in the workplace and beyond, now found itself feeling voiceless as President Trump and the Republican-led Senate, empowered by the altright condemnation of Kavanaugh's accusers, ultimately confirmed him as a new Supreme Court Justice. In addition to the outcome of the Kavanaugh confirmation process, President Trump has helped set the public tone of the white male nationalist movement through his consistent and targeted Twitter attacks on non-white and female politicians, reporters, news commentators, and entertainment performers. This online behavior not only sets a precedent for the messaging of the alt-right and white nationalist movements, but emboldens the members of these movements to continue and enhance that precedent through their own social media harassment campaigns. Social media platforms have shown little interest in addressing this online behavior, possibly because it has become so normalized by the actions of the occupant of the highest office in our nation.

But will future Star Wars films, including the conclusion to the current trilogy, Episode IX: The Rise of Skywalker, continue to react in opposition to the white male nationalist movement and represent society's current anxieties as The Force Awakens and The Last Jedi did, despite online backlash from alt-right and nationalist sources? History would tell us "yes." As Susan Sontag argued, these "world-wide anxieties" consistently manifest themselves in our movies, especially those in the genre of science fiction. And JJ Abrams, director of The Force Awakens, will be rejoining Kathleen Kennedy, hopefully ensuring the continuation of the consistent (and 
intensifying) messaging from the first two films. But whatever the final result of Episode IX will be, the filmic responses to the anxieties over white male nationalism are coming. And just as Christine Cornea questioned how these anxieties would make their way into films in the wake of Trump's election, we must now ponder the same question in the wake of the enactment of Trump's white male nationalist agenda. Will we see a more diverse representation of women and people of color in narratives that traditionally excluded them? Will we see more emphasis on changing the future rather than preserving the past? Will the alt-right and white male nationalist movement continue to serve as the antagonist forces in these movies? These questions will soon be answered by future filmmakers, hopefully inspired by Episodes VII and VIII, just as the boy looking toward the sky at the end of The Last Jedi was inspired by the tales of the Resistance. But do these films serve as a sufficient foundation from which filmmakers can continue to build a cinematic rebellion against white nationalism? Leia would tell them that they have everything they need.

\section{Notes}

${ }^{1}$ Evans, Nicholas. "The alt-right is wrong about Star Wars." The Boston Globe. Dec. 14, 2016, Acessed online. https://www.bostonglobe.com/opinion/2016/12/14/the-alt-right-wrong-aboutstar-wars/NOSKiwttozo4wCYhmAhvaM/story.html

${ }^{2}$ Sontag, Susan. "The Imagination of Disaster." Commentary 40, no. 4 (196), 1965. 42-48.

3 Cornea, Christine. "From Isolationism to Globalism: An Overview of Politics and Ethics in the Hollywood Science Fiction Film." Science Fiction, Ethics and the Human Condition, 159-179. Springer, Cham, 2017.

4 Taub, Amanda. “'White Nationalism,' Explained.” The New York Times. Nov 21, 2016. Accessed online.

https://www.nytimes.com/2016/11/22/world/americas/white-nationalism-explained.html

5 Pitofsky, Marina. "Are Women Changing 'Unite the Right' or Just 'rebranding' the Movement?" USA Today. Aug 10, 2018. Accessed online..

https://www.usatoday.com/story/news/2018/08/o9/women-unite-right-rally2018/874631002/

${ }^{6}$ Martinson, Jane. “Star Wars new female character 'extremely significant', says producer.” The Guardian. Oct 14, 2015. Accessed online.

https://www.theguardian.com/film/2015/oct/14/star-wars-new-female-character-extremelysignificant-says-producer

7 Schatz, Thomas. “The New Hollywood.” Ed. Jim Collins, Ava Preacher Collins, Hilary Radner. Film Theory Goes to the Movies, 299. Routledge, 2012.

${ }^{8}$ Frankel, Valerie Estelle. Star Wars Meets the Eras of Feminism: Weighing All the Galaxy's Women Great and Small. Lanham. Maryland: Lexington Books, 2018, viii. 
9 Salam, Maya. "What is Toxic Masculinity?" The New York Times. Jan. 22, 2019. Accessed online. https://www.nytimes.com/2019/01/22/us/toxic-masculinity.html

${ }^{10}$ Hawkes, Rebecca. "Less Rey, More Kylo Ren: Star Wars Toymaker Told to Avoid Female Characters." The Telegraph. Jan 21, 2016. Accessed online. https://www.telegraph.co.uk/film/star-wars-the-force-awakens/toys-wheresrey-monopoly$\underline{\text { hasbro/ }}$

${ }^{11}$ Frankel, viii.

${ }^{12}$ Dittmer, Jason. "American Exceptionalism, Visual Effects, and the Post-9/11 Cinematic Superhero Boom." Environment and Planning D: Society and Space 29, no. 1 (2011). 114.

${ }^{13}$ Frankel, viii.

${ }^{14}$ Grosz, Elizabeth A. Volatile bodies: Toward a Corporeal Feminism. Indiana University Press, 1994.

${ }^{15}$ Sharf, Zack. "Alt-Right Group Takes Credit for 'The Last Jedi' Backlash, Bashes 'Star Wars' for Including More Women.” IndieWire. Dec 21, 2017. Accessed online.

https://www.indiewire.com/2017/12/star-wars-last-jedi-backlash-alt-right-female-characters$1201910095 /$

${ }^{16}$ Kestenbaum, Sam. "'Alt-Right' Hopes to Rebrand Emperor of 'Star Wars' as Donald TrumpStyle Hero for White Supremacists." Forward. Dec 8, 2016. Access online.

https://forward.com/news/356506/in-search-for-new-recruits-alt-right-cast-their-hero-trumpas-dark-emperor/

${ }_{17}$ USA, Turning Point. “Zip, Zero, Zilch, Nada \#SocialismSucks Pic.twitter.com/coB1JZ172G.” Twitter, May 19 2019. Accessed online. www.twitter.com/TPUSA/status/1130220085455609861

\section{IMAGE CREDITS}

FIG. 1. Image of the KKK logo, Public domain:

https://commons.wikimedia.org/wiki/File:White Pride World Wide -

Stormfront hate symbol.svg

FIG. 2. Image of the First Order logo, Licensed: MesserWoland vectorization of image by User: JLanzer, "vectorization of File: Banner_of_the_First_Order_(Star_Wars).png. October $20^{\text {th }}$, 2015. Licensed under the Creative Commons Attribution-Share Alike 4.0 International license. Accessed online. https://commons.wikimedia.org/wiki/File:Emblem of the First Order.svg

FIG. 3. Screenshot by author of scene from Star Wars Episode VIII: The Last Jedi, Fair use. 